\title{
Evolution of plant RNA polymerase IV/N genes: evidence of subneofunctionalization of duplicated NRPD2/NRPE2-like paralogs in Viola (Violaceae)
}

Thomas Marcussen ${ }^{1}$, Bengt Oxelman², Anna Skog ${ }^{1}$, Kjetill S Jakobsen ${ }^{1 *}$

\begin{abstract}
Background: DNA-dependent RNA polymerase IV and V (Pol IV and V) are multi-subunit enzymes occurring in plants. The origin of Pol V, specific to angiosperms, from Pol IV, which is present in all land plants, is linked to the duplication of the gene encoding the largest subunit and the subsequent subneofunctionalization of the two paralogs (NRPD1 and NRPE1). Additional duplication of the second-largest subunit, NRPD2/NRPE2, has happened independently in at least some eudicot lineages, but its paralogs are often subject to concerted evolution and gene death and little is known about their evolution nor their affinity with Pol IV and Pol V.

Results: We sequenced a 1500 bp NRPD2/E2-like fragment from 18 Viola species, mostly paleopolyploids, and 6 non-Viola Violaceae species. Incongruence between the NRPD2/E2-like gene phylogeny and species phylogeny indicates a first duplication of NRPD2 relatively basally in Violaceae, with subsequent sorting of paralogs in the descendants, followed by a second duplication in the common ancestor of Viola and Allexis. In Viola, the mutation pattern suggested (sub-) neofunctionalization of the two NRPD2/E2-like paralogs, NRPD2/E2- $a$ and NRPD2/E2- $b$. The $d_{N} / d_{S}$ ratios indicated that a 54 bp region exerted strong positive selection for both paralogs immediately following duplication. This $54 \mathrm{bp}$ region encodes a domain that is involved in the binding of the Nrpd2 subunit with other Pol IVN subunits, and may be important for correct recognition of subunits specific to Pol IV and Pol V. Across all Viola taxa 73 NRPD2/E2-like sequences were obtained, of which 23 (32\%) were putative pseudogenes - all occurring in polyploids. The NRPD2 duplication was conserved in all lineages except the diploid MELVIO clade, in which NRPD2/E2- $b$ was lost, and its allopolyploid derivates from hybridization with the CHAM clade, section Viola and section Melanium, in which NRPD2/E2-a occurred in multiple copies while NRPD2/E2-b paralogs were either absent or pseudogenized.
\end{abstract}

Conclusions: Following the relatively recent split of Pol IV and Pol V, our data indicate that these two multisubunit enzymes are still in the process of specialization and each acquiring fully subfunctionalized copies of their subunit genes. Even after specialization, the NRPD2/E2-like paralogs are prone to pseudogenization and gene conversion and NRPD2 and NRPE2 copy number is a highly dynamic process modulated by allopolyploidy and gene death.

\footnotetext{
* Correspondence: k.s.jakobsen@bio.uio.no

${ }^{1}$ Centre for Ecological and Evolutionary Synthesis (CEES), Department of Biology, University of Oslo, 0316 Oslo, Norway
} 


\section{Background}

Eukaryotes normally possess three nuclear DNA-dependent RNA polymerases (Pols), Pol I-III, functionally specialized for synthesis of different types of RNA and thus essential for viability. The Pol holoenzymes consist of about 12 subunits, of which the two largest are tightly bound and together constitute the catalytic seat of the enzyme and are generally polymerase-type specific [1-4]. Angiosperms (flowering plants) are unique in possessing two additional RNA polymerases that are not essential for viability, Pol IV and Pol V (previously called Pol IVa and IVb, or RNAP IVa and IVb). They are functionally distinct, with Pol IV being required for 24 nt siRNA production and Pol V for siRNA-mediated gene silencing of transposons and other repeated elements [5].

The subunit nomenclature of nuclear RNA polymerases has varied among research groups and organisms, and is often in conflict with names for unrelated genes. In the following, we have therefore adopted the 4-letter gene names registered with The Arabidopsis Information Resource. By convention the largest subunits of Pol I, II, III, IV and V are Nrpa1, Nrpb1, Nrpc1, Nrpd1 and Nrpe1 respectively, and the genes encoding these are NRPA1, NRPB1, NRPC1, NRPD1 and NRPE1, respectively. Likewise, the genes encoding the secondlargest subunits of the five polymerases are designated NRPA2, NRPB2, NRPC2, NRPD2 and NRPE2, respectively.

The genes encoding the largest and second-largest subunits of Pol IV, NRPD1 and NRPD2 respectively, originated by independent duplication of their Pol II homologs, NRPB1 and NRPB2. The NRPB1/NRPD1 duplication is shared by both charophytes and embryophytes while the NRPB2/NRPD2 duplication is found only in embryophytes [3]. While Pol IV is found in all plants, Pol V appears to exist only in angiosperms (flowering plants) following duplication of, at least, the largest subunit gene (NRPD1/NRPE1) basally in this lineage [3]. A recent study in the eudicot angiosperm Arabidopsis thaliana confirms the close relationship of Pol IV and Pol V with Pol II and shows that many of their 12 subunits are shared among these three RNA polymerases [1]. Nevertheless, 4 subunits of Pol IV and 6 subunits of Pol V are distinct from their Pol II paralogs, and Pol IV and Pol V differ in 4 subunits. Interestingly, 3 duplicated Pol IV/V genes (third, seventh and nineth largest subunits) appear to be incompletely subfunctionalized with respect to Pol IV and Pol V. These have a higher sequence similarity than the fully specialized gene pairs (e.g. NRPD1/NRPE1) and are presumably derived from more recent duplication events.

Following the duplication and specialization of the Pol IV/V largest subunit genes (NRPD1/NRPE1) in angiosperms, duplication of the second-largest subunit genes (NRPD2/E2) seems comparatively rare. NRPD2/E2 is apparently a singleton in monocots (Oryza, Zea) as well as in several families of eudicots, e.g., Aceraceae (Acer), Asteraceae (Carthamus), Lamiaceae (Galeopsis; Brysting AK, unpublished), Myrtaceae (Myrtus), Solanaceae (Solanum) and Vitaceae (Vitis) [3,6-8]. A few eudicot lineages, however, possess duplicate NRPD2/E2 copies, e.g., Brassicaceae (Arabidopsis; but only one paralog is expressed), Caprifoliaceae (Lonicera), Celastraceae (Maytenus), Euphorbiaceae (Manihot), Salicaceae (Populus; but only one paralog is expressed), Caryophyllaceae (Silene and many other genera) and Violaceae (Viola and Allexis; herein) [6,9-11]. This indicates that duplicated NRPD2/E2 genes may in fact be a common feature in eudicots. It is clear that the NRPD2/E2 duplications have occurred independently in these lineages, and that they are also frequently lost, with sorting among lineages as a common result [10].

The mechanisms behind gene duplication are well known in eukaryotes and in plants [e.g., [12]]. While it is clear that by far the most likely fate of a duplicate gene is gene death $[7,13,14]$, mechanisms accounting for the duplications being retained in the genome have been, until recently, less well understood [15]. Duplicate genes may be preserved by a neutral mechanism in which each paralog accumulates loss-of-function mutations (degeneration) that are complemented by the other copy. Such mutations can happen either at the regulatory level, causing the paralogs to diverge in pattern of expression (duplication-degeneration-complementation (DDC) [16]), or at the product level, causing the paralogs to diverge in function (subfunctionalization [17]). Furthermore, either mechanism can eliminate possible structural trade-offs imposed by different functions performed by a multifunctional gene [18], by unlinking these functions. These mechanisms can thus be regarded as prerequisites for the ability of duplicate genes to specialize and acquire new functions (subneofunctionalization [19]). Regulatory and functional subfunctionalization are both well-documented in gene families, in eukaryotes in general as well as in plants [e.g., [15,20-23]].

The RNA polymerase subunit encoded by NRPD2/E2, Nrpd2/Nrpe2, has a discrete double function in angiosperms, assembling either with Pol IV or with Pol V. A duplication of this gene might have been preserved if the two paralogs underwent subfunctionalization with respect to Pol type, and would have required some degree of co-evolution of co-assembling subunits.

In this study we have investigated the evolution of NRPD2/E2-like genes within the Violaceae (Malpighiales), with particular reference to the genus Viola 


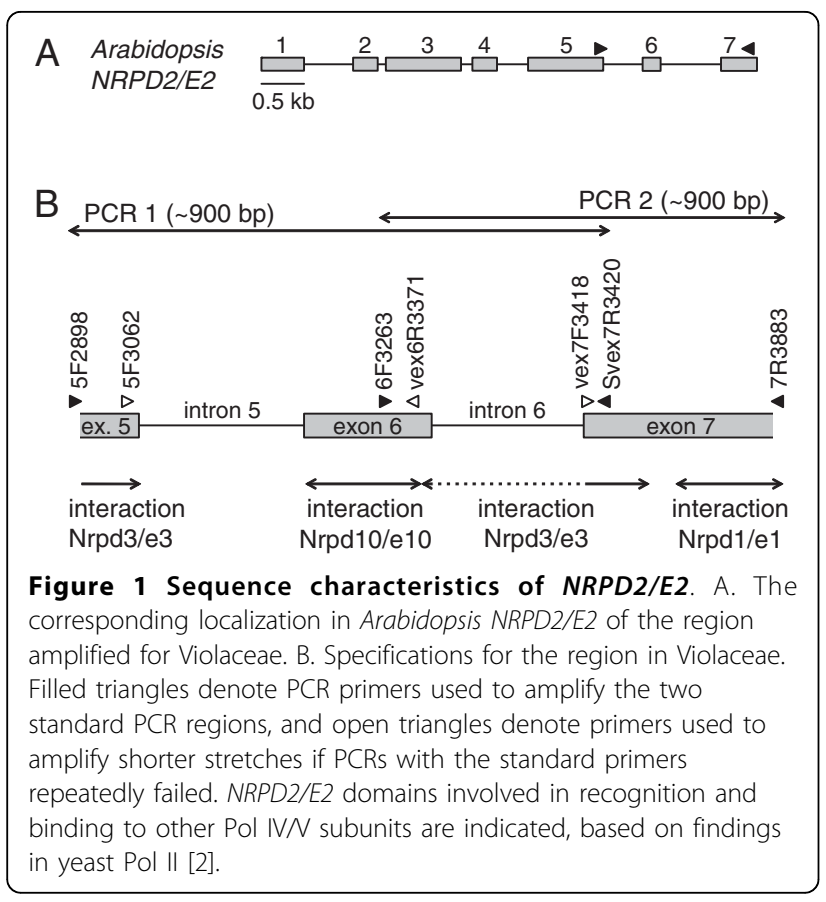

(Figure 1). This gene occurs in a single copy in most genera of the family but it is duplicated in others (Allexis and Viola). In a similar system within tribe Sileneae of the Caryophyllaceae (Caryophyllales), concerted evolution was found to be prominent among NRPD2/E2 paralogs [10]. In that study, however, only intron 6 was investigated. In order to be able to examine possible neofunctionalization among NRPD2/E2-like duplicants in the Violaceae system, we have expanded this range to include also the flanking exons of intron 6 .

The Violaceae consist of some 900 species in 23 mostly tropical genera [24]. Their relationships have recently been examined in a phylogenetic study based on plastid and nuclear ribosomal gene DNA sequences [25]. With more than 500 species, Viola is the largest genus of the Violaceae and the only one widely distributed in the northern hemisphere [26]. Based on chromosome counts [e.g., [27]] and isozyme expression data [28,29] it can be estimated that roughly two thirds of Viola species belong to paleopolyploid lineages having secondary base numbers ranging from $x=10$ to $x=27$ or higher. "True" diploids are known only from two sections, Andinium $(x=7)$ from South America [30] and Chamaemelanium $(x=6)$ which is mainly northern amphi-Pacific [e.g., [31]]. Tentative genus phylogenies have been based on rRNA Internal Transcribed Spacer (ITS) sequence data in several studies [e.g., [26,32]] but this marker has proven of no use for recovering any of these polyploid relationships [e.g., [33]]. The genus phylogeny is currently being re-examined using low-copy nuclear genes (Marcussen, Oxelman, Jakobsen, unpublished data).
In Arabidopsis five of the 12 genes associated with Pol IV/V have been duplicated, apparently independently, and have undergone subfunctionalization with respect to Pol IV and V [cf. [1]]. For NRPD2/E2 in eudicots, available sequence information suggests numerous independent duplications and that these paralogs are often subject to concerted evolution and gene death [10]. In this study, we elucidate the origin of duplication of the NRPD2/E2-like genes within the Violaceae and aspects of its evolution and phylogeny within Viola. Polyploidy, which is known to be a major evolutionary process in Viola, could be thought to interact with a nascent gene family such as NRPD2/E2. For instance, could redundancy resulting from polyploidy destabilize the incipient differentiation of the two paralogs, NRPD2/E2- $a$ and $N R P D 2 / E 2-b$, or could the occasional loss of primary duplication be compensated for by secondary duplications resulting from polyploidy? The immediate consequence of gene duplication is redundancy, which will generally lead to loss or pseudogenization of one paralog unless the paralogs become subfunctionalized or neofunctionalized. Positive selection can be taken as evidence of neofunctionalization. It is therefore of relevance to detect to what degree positive selection has acted on duplicated NRPD2/E2-like paralogs within the Violaceae, and if it has, at which sites and on which phylogenetic branches.

\section{Results}

\section{Assignment and naming of NRPD2/E2-like homologs} in Violaceae

$N R P D 2 / E 2-a$ and NRPD2/E2- $b$ are arbitrary labels that denote the two paralogs found in Viola and Allexis. They do not reflect orthology to duplicated NRPD2/E2 loci outside of Violaceae, and do not imply that the respective binding specificities of the paralogs to Pol IV and Pol V are known. Appended digits to the sequence name separate homoeologs of a paralog within a single specimen (e.g., banksii_B2 refers to homoeolog 2 of NRPD2/E2-b in V. banksii).

\section{NRPD2/E2-like homologs in Violaceae}

GenBank sequence data for the Malpighiales demonstrate duplicate copies of NRPD2/E2 in both Manihot esculenta (CK652029, DV448133) and Populus trichocarpa (e.g., DT509274, CV227572) but not in Euphorbia esula (DV145650). In Manihot both paralogs are potentially functional but in Populus one paralog (CV227572) is characterized by frameshift and non-synonymous mutations not reconcilable with NRPD2/E2 activity. The two copies found in Manihot, Populus and Viola are not orthologous to each other (not shown). We obtained and analyzed sequence information from six non-Viola Violaceae taxa (Table 1). These sequences were aligned 
Table 1 Material and gene sequences used

\begin{tabular}{|c|c|c|c|c|c|}
\hline Species & $\begin{array}{l}\text { Taxonomic group (base } \\
\text { chromosome number) }\end{array}$ & $2 n$ & $x$ & GenBank accession ID & Voucher ID \\
\hline Viola congesta & sect. Andinium $(x=7)$ & - & $2 x$ & a: GU289564; b: GU289615 & Marcussen $641(0)$ \\
\hline Viola biflora & sect. Chamaemelanium $(x=6)$ & $2 n=12$ & $2 x$ & a: GU289574; b: GU289625 & Marcussen $775(\mathrm{O})$ \\
\hline Viola brevistipulata & sect. Chamaemelanium $(x=6)$ & $2 n=12$ & $2 x$ & $\begin{array}{l}\text { a: GU289575; b: GU289626, } \\
\text { GU289627 }\end{array}$ & Marcussen $803(0)$ \\
\hline Viola canadensis & sect. Chamaemelanium $(x=6)$ & $2 n=12,24$ & $4 x$ & $a^{a}:$ GU289576; ba $:$ GU289637 & Marcussen $802(\mathrm{O})$ \\
\hline Viola nuttallii & sect. Chamaemelanium $(x=6)$ & $2 n=24$ & $4 x$ & $\begin{array}{l}\text { a: GU289577, GU289578, } \\
\text { GU289579; b: GU289628, } \\
\text { GU289629 }\end{array}$ & Marcussen $801(0)$ \\
\hline Viola pubescens & sect. Chamaemelanium $(x=6)$ & $2 n=12$ & $2 x$ & a: GU289580; b: GU289630 & Marcussen $637(0)$ \\
\hline Viola maculata & sect. Chilenium & - & $8 x$ & $\begin{array}{l}\text { a: GU289570, GU289571, } \\
\text { GU289572, GU289573; b: } \\
\text { GU289616, GU289617, } \\
(\text { GU289618 }), \text { GU289619 }\end{array}$ & Marcussen $804(0)$ \\
\hline Viola banksii & sect. Erpetion & - & $8 x-10 x$ & 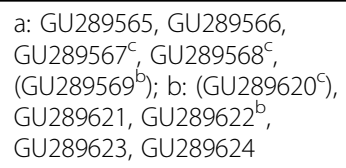 & Marcussen $630(0)$ \\
\hline Viola bicolor & sect. Melanium & $2 n=34$ & $12 x ?$ & $\begin{array}{l}\text { a: GU289603, GU289604, } \\
\text { GU289605', GU289606 }{ }^{\text {' }} \text { ' } \\
\text { GU289607', GU289608 }\end{array}$ & Marcussen $743(\mathrm{O})$ \\
\hline Viola calcarata & sect. Melanium & $2 n=20$ & $12 x ?$ & $\begin{array}{l}\text { a: GU289609, GU289610, } \\
\text { GU289611, GU289612c, } \\
\text { GU289613, GU289614 }\end{array}$ & Marcussen $672(0)$ \\
\hline Viola dirimliensis & sect. Melanium & $2 n=8$ & $8 x ?$ & $\begin{array}{l}\text { a: GU289599, GU289600, } \\
\text { GU289601, GU289602 }\end{array}$ & Marcussen $650(0)$ \\
\hline Viola epipsila & sect. Viola $(x=10,12)$ & $2 n=24$ & $4 x$ & $\begin{array}{l}\text { a: GU289587, GU289588; } \\
\text { b: GU289635 }\end{array}$ & Marcussen $661(\mathrm{O})$ \\
\hline Viola hirta & sect. Viola $(x=10,12)$ & $2 n=20$ & $4 x$ & a: GU289581, GU289582 & Marcussen $682(0)$ \\
\hline Viola mirabilis & sect. Viola $(x=10,12)$ & $2 n=20$ & $4 x$ & $\begin{array}{l}\text { a: GU289583, GU289584; } \\
\text { b: GU289631 }\end{array}$ & Marcussen $683(0)$ \\
\hline Viola selkirkii & sect. Viola $(x=10,12)$ & $2 n=24$ & $4 x$ & $\begin{array}{l}\text { a: GU289589, GU289590; } \\
\text { b: GU289634 }\end{array}$ & Marcussen $698(0)$ \\
\hline Viola spathulata & sect. Viola $(x=10,12)$ & - & $8 x ?$ & $\begin{array}{l}\text { a: GU289593, GU289594, } \\
\text { GU289595 , GU289596 } \\
\text { GU289597, GU289598; b: } \\
\text { GU289636 }\end{array}$ & Marcussen $670(\mathrm{O})$ \\
\hline Viola uliginosa & sect. Viola $(x=10,12)$ & $2 n=20$ & $4 x$ & $\begin{array}{l}\text { a: GU289585, GU289586; } \\
\text { b: GU289632 }\end{array}$ & Marcussen $662(\mathrm{O})$ \\
\hline Viola verecunda & sect. Viola $(x=10,12)$ & $2 n=24$ & $4 x$ & $\begin{array}{l}\text { a: GU289591, GU289592; } \\
\text { b: GU289633 }\end{array}$ & Marcussen $697(0)$ \\
\hline Allexis batangae & Violaceae (outgroup) & - & $2 x$ & a: GU289562; b: GU289563c & Bos 4241 (UPS) \\
\hline Anchietea parvifolia & Violaceae (outgroup) & - & $2 x$ & GU289559 & $\begin{array}{l}\text { Myndel Pedersen } \\
13944 \text { (UPS) }\end{array}$ \\
\hline Corynostylis arborea & Violaceae (outgroup) & - & $2 x$ & GU289560 & $\begin{array}{l}\text { Asplund } 14509 \\
\text { (UPS) }\end{array}$ \\
\hline $\begin{array}{l}\text { Cubelium concolor (= } \\
\text { Hybanthus concolor) }\end{array}$ & Violaceae (outgroup) & $2 n=48$ & $2 x$ & GU289561 & $\begin{array}{l}\text { Pläck \& Bodin s.n. } \\
\text { (UPS) }\end{array}$ \\
\hline $\begin{array}{l}\text { Hybanthus } \\
\text { enneaspermus }\end{array}$ & Violaceae (outgroup) & $2 n=16,32$ & $2 x$ & GU289558 & $\begin{array}{l}\text { unknown 2001-05- } \\
13 \text { (UPS) }\end{array}$ \\
\hline Rinorea ilicifolia & Violaceae (outgroup) & - & $2 x$ & GU289557 & $\begin{array}{l}\text { Friis et al. } 2445 \\
\text { (UPS) }\end{array}$ \\
\hline Populus trichocarpa & Salicaceae (outgroup) & $2 n=38$ & - & a: DT509274; b: CV227572 & - \\
\hline Manihot esculenta & Euphorbiaceae (outgroup) & $2 n=36,54,72$ & - & a: DV448133; b: (CK652029) & - \\
\hline
\end{tabular}


Table 1: Material and gene sequences used (Continued)

\begin{tabular}{l} 
Euphorbia esula Euphorbiaceae (outgroup) $2 n=20,48-60-$ \\
\hline Taxa used in this study, with respective GenBank accessions for DNA sequences and voucher information. For each taxon systematic affinity (sections within Viola \\
for ingroup, and families within Malpighiales for outgroup), chromosome counts ( $2 n$, where available), and putative ploidal levels ( $x$, inferred from the NRPD2/E2 \\
data), are indicated. GenBank accession IDs are sorted by paralog (a and b), and by homoeolog (ascending numbers); gene copies excluded from phylogenetic \\
analysis, because they were considered too short for reliable analysis, are put in brackets. Note that NRPD2/E2- $a$ and NRPD2/E2- $b$ are arbitrary labels, and that \\
NRPD2/E2- $a$ and NRPD2/E2- $b$ in Euphorbiaceae, Salicaceae and Violaceae are not orthologous to each other. Herbarium acronyms for voucher specimen \\
deposition (i.e., O, U) follow Holmgren and Holmgren [50]. \\
a the secondarily duplicated gene copies in Viola canadensis differed only in $3($ NRPD2/E2- $a$ ) and 8 (NRPD2/E2- $b$ ) substitutions, and their respective consensuses \\
were used as single sequences in the analyses \\
b partial sequence (exon 6 to exon 7); PCR 1 failed (see Figure 1) \\
c partial sequence (exon 5 to intron 6); PCR 2 failed (see Figure 1)
\end{tabular}

to exon (mRNA) sequences from GenBank of Euphorbia, Manihot and Populus. Outside Viola, we found singleton NRPD2/E2 in all of Anchietea parvifolia, Corynostylis arborea, Cubelium concolor (= Hybanthus concolor), Hybanthus enneaspermus and Rinorea ilicifolia. Like Viola, Allexis batangae had duplicated NRPD2/ $E 2$ genes, but only the NRPD2/E2-b paralog was putatively functional; its NRPD2/E2- $a$ paralog was a pseudogene that contained three frameshift mutations and stop codons in all three reading frames.

Our inferences of the plastid and nuclear ribosomal phylogeny of Violaceae (Figure 2a) were congruent with previous analyses of the family, regarding both general topology [25] and the placement of Cubelium [34]. Rinorea was placed as sister to the rest of the Violaceae, with a Cubelium + Orthion clade and an Allexis + Viola clade as successive sisters to a Hybanthus (Anchietea + Corynostylis) clade. All branches received high (95$100 \%)$ bootstrap support.

The NRPD2/E2 phylogenies (Figure $2 \mathrm{~b}$ ) were incongruent with the species tree. Again, Rinorea was placed as sister to the rest of the Violaceae with relatively high bootstrap support (MP: 71\%/ML: 93\%). Within rest-Violaceae three well-supported clades were found, one consisting of NRPD2/E2-a copy of Allexis and Viola (92\%/ 95\%), a second of the NRPD2/E2-b copy of Allexis and Viola $(92 \% / 96 \%)$, and a third $(67 \% / 76 \%)$ consisting of Hybanthus and Cubelium as sisters to a strongly supported (93\%/100\%) Anchietea + Corynostylis clade. Whether it is Hybanthus (MP) or Cubelium (ML) that is sister to the rest within the last clade depends on the analysis, but neither topology receives strong bootstrap support ( $52 \%$ and $61 \%$, respectively). Weak support is given for an NRPD2/E2- $a+N R P D 2 / E 2-b$ clade (Allexis and Viola; 52\%/68\%). However, the inter-relationships of these three main clades remain elusive and depend on whether Cubelium and Hybanthus are included in the analysis (not shown).

No evidence of recombination was detected in the Violaceae alignment using GARD (see methods). Two possible recombination breakpoints were detected, but the topologies resulting from phylogenetic analyses of the partitions were congruent.

The reconciled tree (Figure 2c), constructed in GeneTree by embedding the NRPD2/E2 tree (Figure $2 \mathrm{~b}$ ) within the species tree (Figure 2a), explains the incongruence between these two trees by hypothesizing two events of gene duplication and three losses. A first duplication was postulated on the basal branch of all Violaceae except Rinorea, meaning that one paralog would have been lost in Viola and Allexis but retained in Cubelium, Hybanthus, Anchietea and Corynostylis. The second paralog may have been retained only in Viola and Allexis, before duplicating a second time in their common ancestor and diversify into their present NRPD2/E2- $a$ and NRPD2/E2- $b$ paralogs.

\section{NRPD2/E2-like homologs in Viola}

There were considerable differences in the relative number of copies of NRPD2/E2- $a$ and NRPD2/E2- $b$ across lineages of the genus Viola (Table 1), but seen as a whole $N R P D 2 / E 2$ always occurred in two or more potentially functional copies. Only the two diploid sections Andinium and Chamaemelanium appeared to have single and functional copies of each of NRPD2/E2$a$ and NRPD2/E2-b. All gene copies appeared functional in the neopolyploids of the latter section ( $V$. nuttallii and $V$. canadensis). Non-functional gene copies were identified by the often numerous occurrence of premature stop codons and frameshift mutations within exons (up to a single 862 bp deletion comprising all of exon 6 in B1_banksii); in a single case (NRPD2/E2-b in V. uliginosa) the sequence was assumed to be non-functional because of a partial duplication within the highly conserved GEMERD amino acid motif of exon 7. Taxa of section Erpetion ( $V$. banksii) and section Chilenium ( $V$. maculata) had equal numbers of NRPD2/E2-a and NRPD2/E2- $b$ copies; 5 and 4 of each, respectively, but differed in their respective numbers of putatively functional copies. All members of the sections Melanium and Viola had unbalanced numbers of NRPD2/E2- $a$ and NRPD2/E2-b. Typically, taxa of section Viola had two 

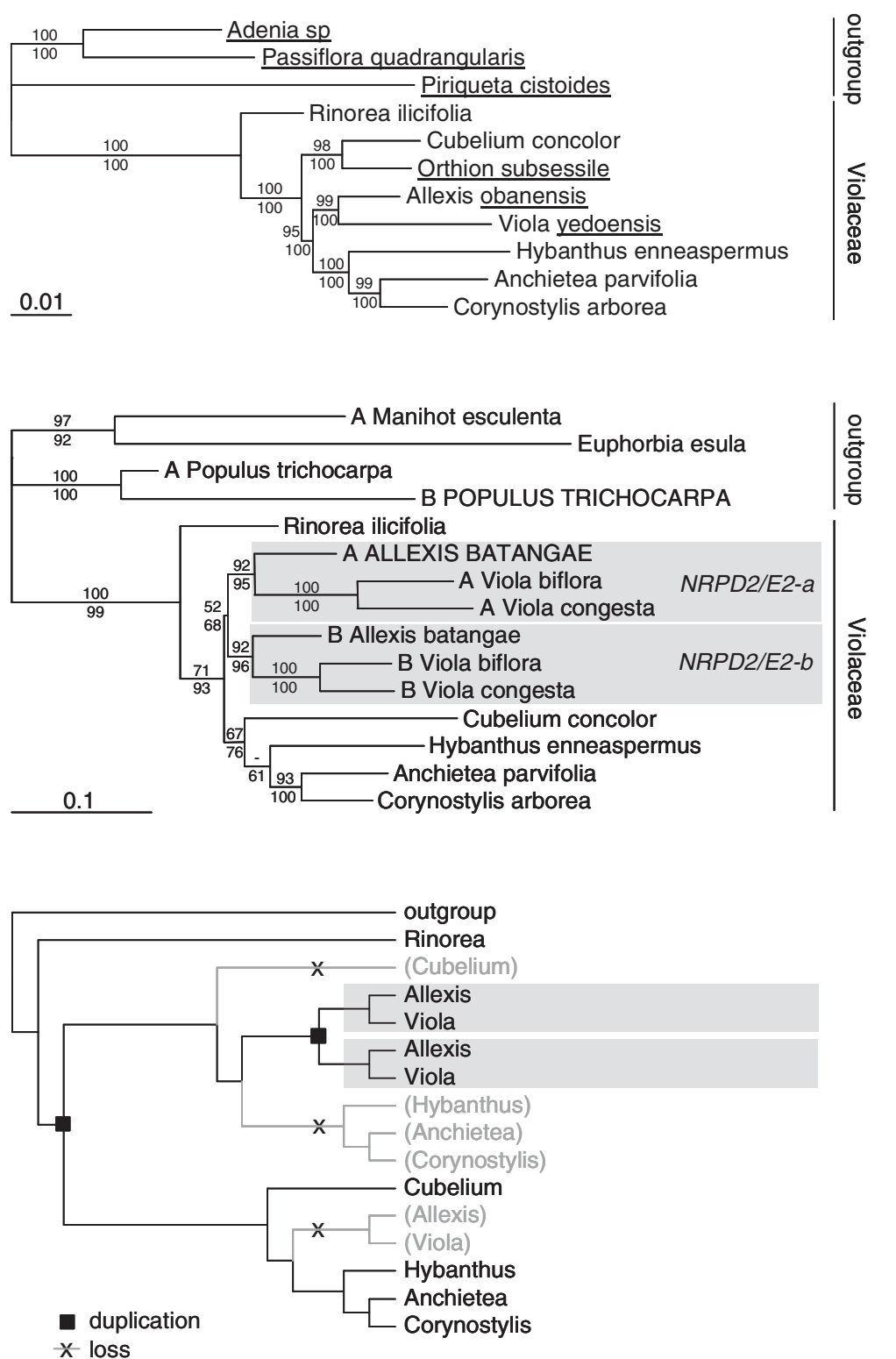

Figure 2 Phylogeny of the NRPD2/E2-like gene family in Violaceae. Bootstrap support values (1000 replicates) are indicated above (MP) and below (ML) branches, respectively. Names of pseudogenes are capitalized. A. Violaceae phylogeny inferred by ML analysis of the four genes atpB, matK, rbcL and 16S. Sequence data were obtained from Tokuoka [25] with an additional matK sequence of Cubelium concolor from GenBank (EF135550, as Hybanthus concolor). Names of taxa not included in phylogeny B are underlined. B. Phylogeny of NRPD2/E2 paralogs in Violaceae inferred by ML analysis. C. Tree reconciliation between the NRPD2/E2 gene tree (B) and the Violaceae organism tree (A), using the GeneTree software. The two inferred gene duplication events and three gene loss events are indicated.

putatively functional copies of NRPD2/E2- $a$ and one non-functional copy of NRPD2/E2-b (except in $V$. hirta and in $V$. spathulata). Members of section Melanium had four to six copies of NRPD2/E2-a, of which one or several could be non-functional, but no copies of $N R P D 2 / E 2-b$. Unbalanced numbers of NRPD2/E2- $a$ and NRPD2/E2-b copies were found also in V. brevistipulata and $V$. nuttallii (section Chamaemelanium) but, in light of their ploidy levels and expected copy number, this likely reflects heterozygosity in one of the NRPD2/E2- $a$ loci ( $V$. nuttallii) or the NRPD2/E2-b locus ( $V$. brevistipulata).

The MP and ML phylogenies of NRPD2/E2- $a$ and $N R P D 2 / E 2-b$ in Viola are all largely congruent (Figure 3 ) with an (as of yet) unpublished phylogeny for the genus based on another low-copy nuclear gene (Marcussen T, Oxelman B, Blaxland K, Jakobsen KS, in prep.), with the exceptions that NRPD2/E2- $b$ is absent in the 


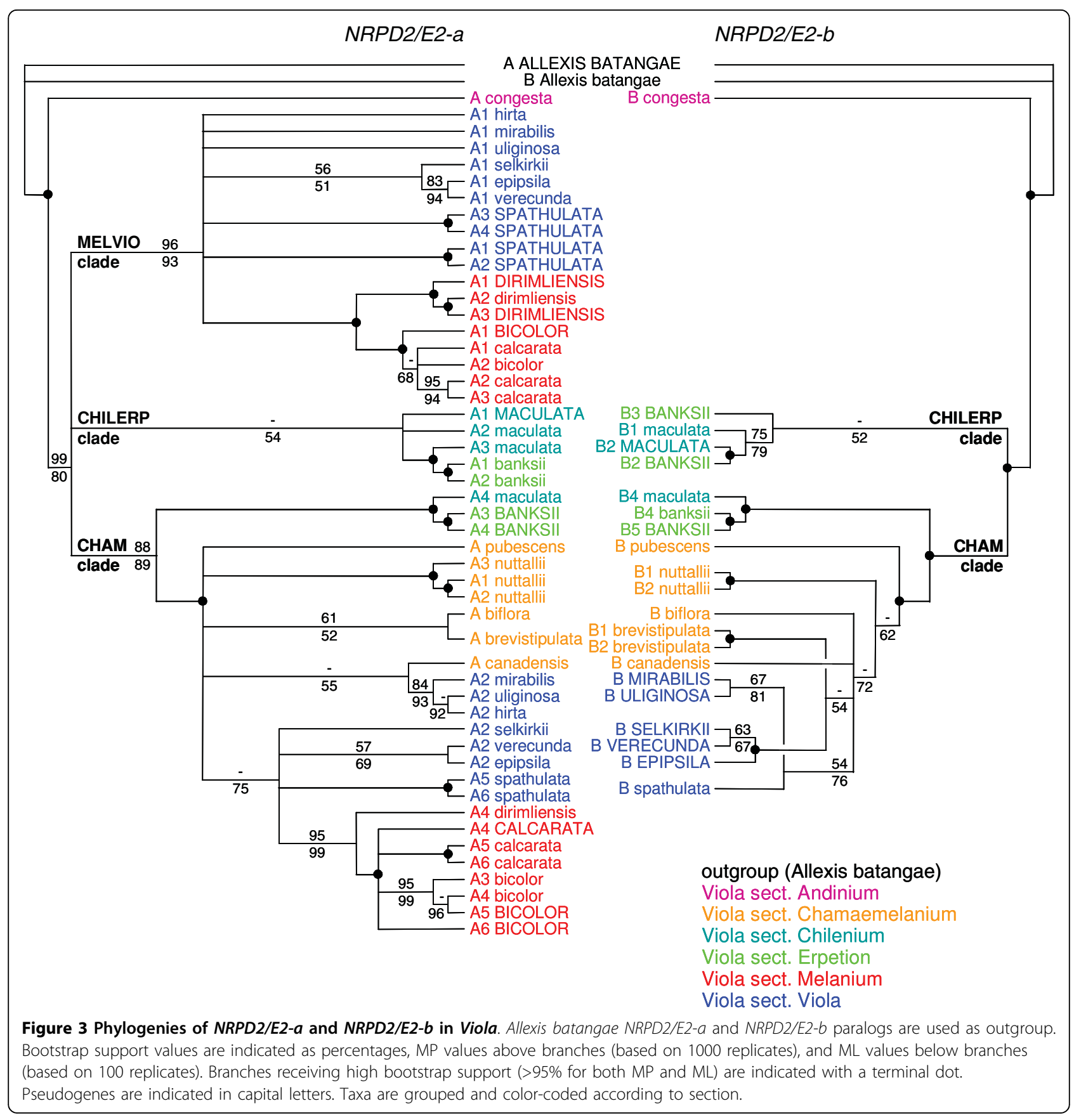

MELVIO clade, in the entire section Melanium and in $V$. hirta of section Viola. Generally higher bootstrap support was obtained for NRPD2/E2- $b$ than for NRPD2/ $E 2-a$, reflecting that the former has ca $200 \mathrm{bp}$ longer introns and therefore more phylogenetically informative sites. Working our way up from the root of the two consensus trees in Figure 3, V. congesta (section Andinium) is sister to the rest of the genus, sandwiched by branches receiving strong bootstrap support in all analyses. Next comes a polytomy of three lineages, here referred to as CHILERP, MELVIO (only NRPD2/E2-a) and CHAM. The CHILERP clade, which received only weak ML bootstrap support, but was recovered for both NRPD2/E2- $a$ (54\%) and NRPD2/E2-b (52\%), consisted of various $V$. banksii (section Erpetion) and $V$. maculata (section Chilenium) lineages, of which one internal mixed species lineage received 100\% bootstrap support. The MELVIO clade, missing for NRPD2/E2- $b$, received strong support for NRPD2/E2-a (MP: 96\%/ML: 93\%) and consisted of a basal polytomy of taxa of section 
Viola within which a strongly supported (100\%) section Melanium is nested. The large and strongly supported CHAM clade included sequences from all represented sections except Andinium and, in the case of NRPD2/ E2-b, Melanium. A basal dichotomy in the CHAM clade lead to two strongly supported sub-clades: one subclade consisting of one $V$. maculata sister to two $V$. banksii sequences, and a second sub-clade in which taxa of sections Chamaemelanium and Viola formed a polytomy; in NRPD2/E2-a section Melanium was a monophyletic group (92\%/99\%) within this basal polytomy. Within the polytomies of CHAM and MELVIO the species constellation of ( $V$. mirabilis $(V$. uliginosa $+V$. hirta), (V. epipsila $+V$. selkirkii $+V$. verecunda), and $V$. dirimliensis sister to the rest of section Melanium were common.

\section{Selective forces}

The pattern of change of $d_{N} / d_{S}$ ratios along the sequence is shown in Figure 4, using the sliding window option for pairwise comparison of Rinorea with three data sets: (1) 3 NRPD2/E2 sequences from Cubelium/ Corynostylis/Hybanthus, in which the gene is not duplicated; (2) 13 NRPD2/E2-a sequences from Allexis and Viola; and (3) 10 NRPD2/E2-b sequences from Viola. The $d_{N} / d_{S}$ ratios are well below 1 throughout most of the sequence for Cubelium/Corynostylis/Hybanthus, thus indicating purifying selection. It is for the most

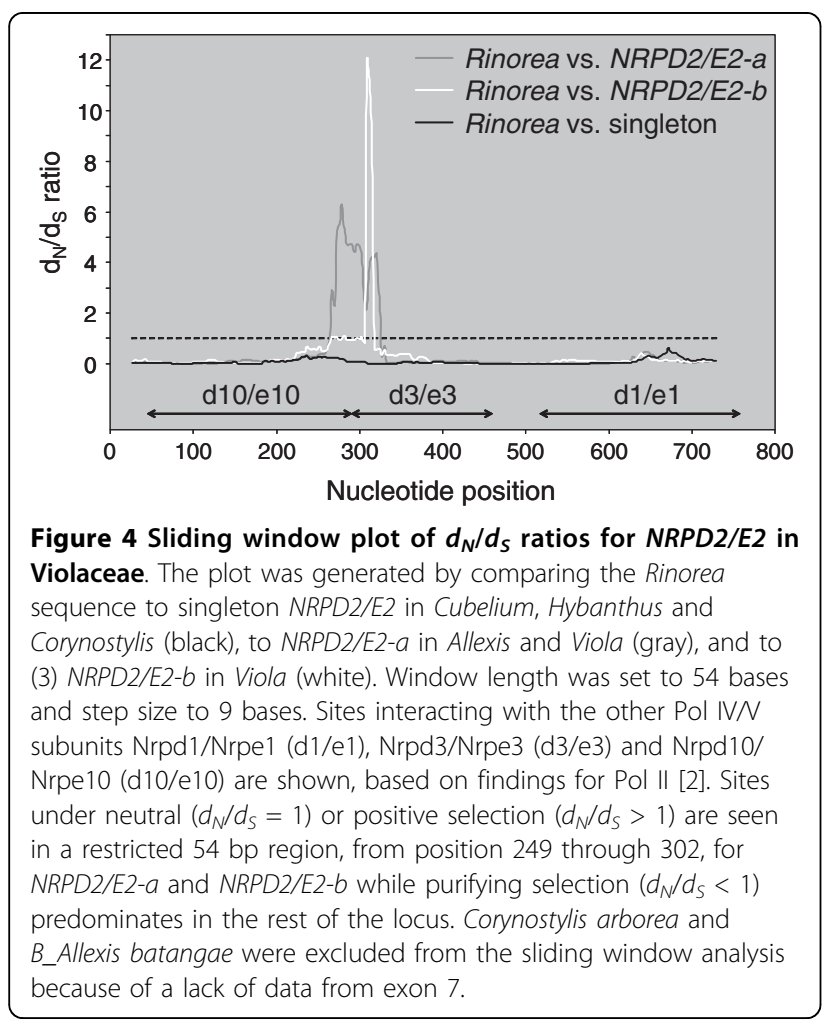

part also so for NRPD2/E2- $a$ and NRPD2/E2- $b$, but for both paralogs a $54 \mathrm{bp}\left(18\right.$ amino acid) region with $d_{N} /$ $d_{S}$ considerably higher than 1 is identified near the 3' end of exon 6 (nucleotide positions 249 through 302), indicating positive selection in both these paralogs. Within the region of positive selection a compensatory pattern conserving regionally the net charge of mutations was found (not shown): substitution of E/D (glutamic acid/aspartic acid) in position 300 is compensated for by gain of $\mathrm{E}$ in position 252 in NRPD2/E2-b. Thus, the positions of charged amino acids are subject to selection.

The $54 \mathrm{bp}$ region where positive selection was detected (Figure 4) was further analyzed using the CodeML software of the PAML package for estimating $d_{N} / d_{S}$ ratios of 60 specified branches in the predefined phylogenetic tree. A 60-parameter model, assuming one $d_{N} / d_{S}$ ratio for each branch, was found to marginally better fit the data $(p=0.0516)$ than a single-parameter model, assuming a uniform $d_{N} / d_{S}$ ratio across all branches in the tree. Although many branches in the tree had positive $d_{N} / d_{S}$ ratios, especially those immediately after the duplication basal to Allexis and Viola, only for the branch basal to $B_{-}$congesta was the $d_{N} / d_{S}$ ratio significantly larger than $1(p=0.0526)$. A model assuming a common $d_{N} / d_{S}$ ratio for the three basalmost branches following the duplication, i.e. basal to A_Allexis, A_congesta and $B$ _congesta, received strong support $(p=0.0101)$. Thus, both NRPD2/E2 paralogs seem to have been subjected to positive selection $\left(d_{N}\right.$ $>d_{S}$ ) soon after the duplication, but apparently not at exactly the same time (Figures 5 and 6). For NRPD2/E2$a$, positive selection is hypothesized (i) immediately after the duplication of $N R P D 2 / E 2$ and before the split of Allexis and Viola, and (ii) within the rest of Viola after Viola section Andinium split off, and finally (iii) also within the CHAM clade. For NRPD2/E2- $b$ positive selection occurred somewhat later, and only in the branch leading to Viola (i.e. not in Allexis).

\section{Discussion}

\section{NRPD2/E2 phylogeny within Violaceae}

The NRPD2/E2- $a$ and NRPD2/E2- $b$ phylogenies differ in several respects from the already published organism phylogenies for Viola $[26,32,35]$, based solely on the nuclear ITS region, and for Violaceae [25], based on 4 nuclear and chloroplast regions. Our results indicate that, at the family level, this incongruence is due to duplication of NRPD2/E2 and the uneven sorting of paralogs among lineages (Figure 2). Within Viola, the incongruence appears to result partly from the notorious failure of ITS to capture allopolyploid relationships, a common consequence of gene conversion among the often thousands of copies of this gene within the plant 


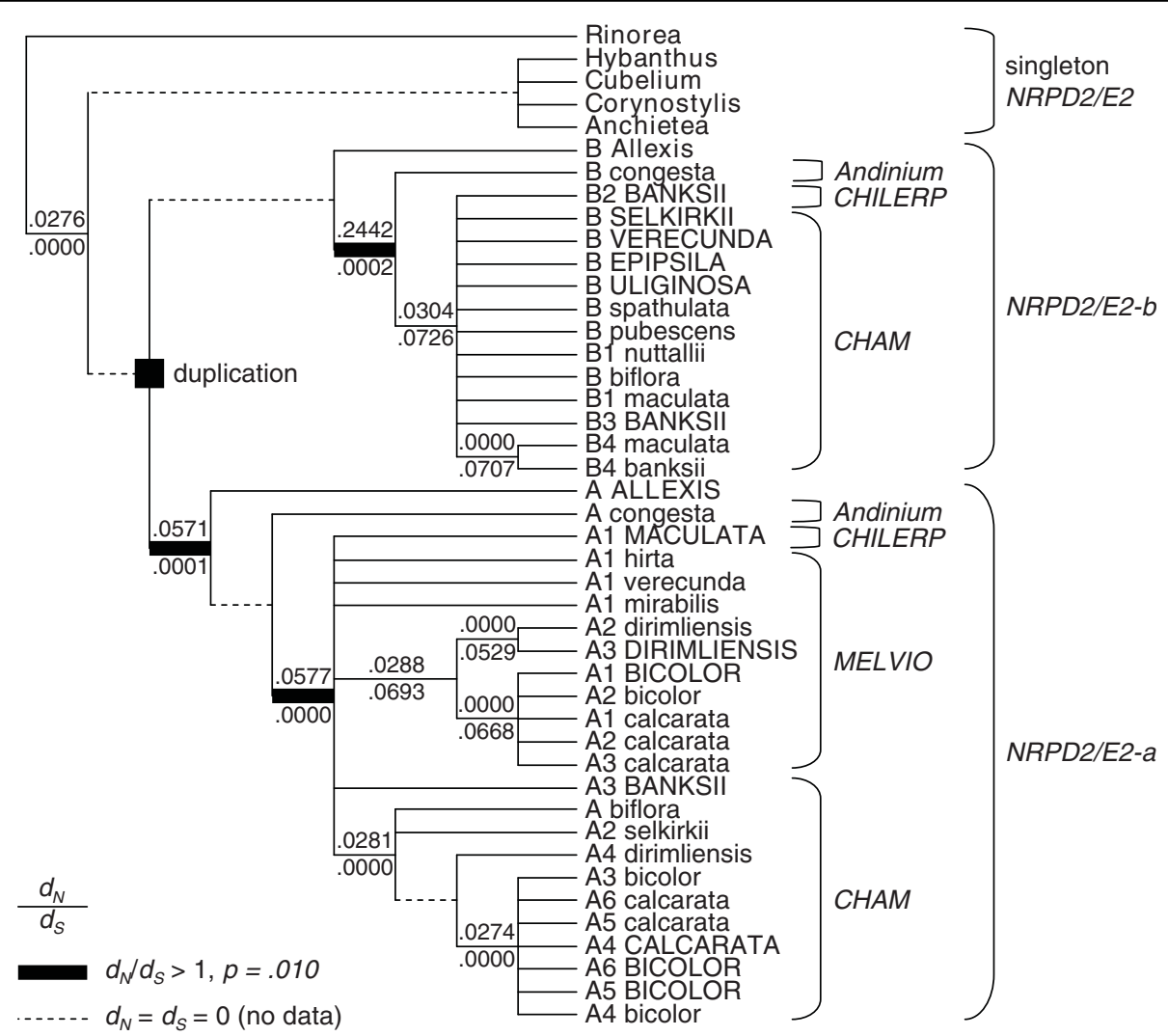

Figure $5 d_{N}$ and $d_{S}$ estimated for NRPD2/E2- $a$ and NRPD2/E2-b along individual branches in the Violaceae phylogeny. Values of $d_{N}$ (above branches) and $d_{S}$ (below branches) along each branch were estimated by using the free-ratio model using the CodeML program in PAML [49]. For the branches drawn with bold lines, $d_{N} / d_{S}$ was larger than $1(p=0.010)$ under a 2-rate model, which suggests that positive selection acted on these lineages. Branches collapsing in a MP phylogenetic analysis of the 54 bp region are indicated with broken lines. NRPD2/ E2 duplication in the common ancestor of Allexis and Viola is indicated. Only species names are shown for Viola, and non-Viola taxon names are shown in boldface. Pseudogenes are indicated with capital letters.

genome [33], and partly from the evolutionary unstable copy number of NRPD2/E2 (Figure 3). A genus phylogeny based on low-copy nuclear genes is currently being constructed and is largely congruent with the NRPD2/ E2-a phylogeny (Marcussen T, Oxelman B, Blaxland K, Jakobsen KS, in prep.).

In comparison with an organism phylogeny of Violaceae, based on data from Tokuoka [25] with an extra accession of Cubelium $r b c \mathrm{~L}$, our data suggest that NRPD2/E2 was duplicated twice within the evolutionary history of the family. The reconciled GeneTree phylogeny (Figure $2 \mathrm{C}$ ) indicated a first duplication relatively basally in the family, after the split of Rinorea, with subsequent complete sorting of paralogs in the descendant genera. so that one paralog was retained in Cubelium, Hybanthus, Anchietea and Corynostylis, and the second paralog was retained in Allexis and Viola. This interpretation, however, entirely rests on the conflicting phylogenetic position of Cubelium in the species phylogeny, which received strong bootstrap support (MP: 98\%, ML: $100 \%$ ), versus in the NRPD2/E2 phylogeny which was less strongly supported (MP: 67\%, ML: 76\%). On the other hand, we found no evidence that this incongruence resulted of recombination.

The second duplication event, in the common ancestor of the genera Allexis and Viola, is incontestable because it is retained in most of the descendants. Lineage sorting of paralogs may, however, also explain the phylogenetic pattern and link the two duplication events. The first duplication may in fact have persisted in the lineage leading to Allexis and Viola, but been subject to an event of sequence replacement in the common ancestor of these two genera. Either scenario would appear in the phylogeny as an independent duplication basal to Allexis and Viola.

Interestingly, for the Caryophyllaceae it has not been possible to trace back the origin of the NRPD2/E2 duplication event either. Judging by paralog similarity, the duplication in tribe Sileneae seems to be a relatively recent one and may well have occurred within this tribe [10]. In contrast, Cerastium, which belongs to another subfamily [36], has NRPD2/E2-a and NRPD2/E2-b 


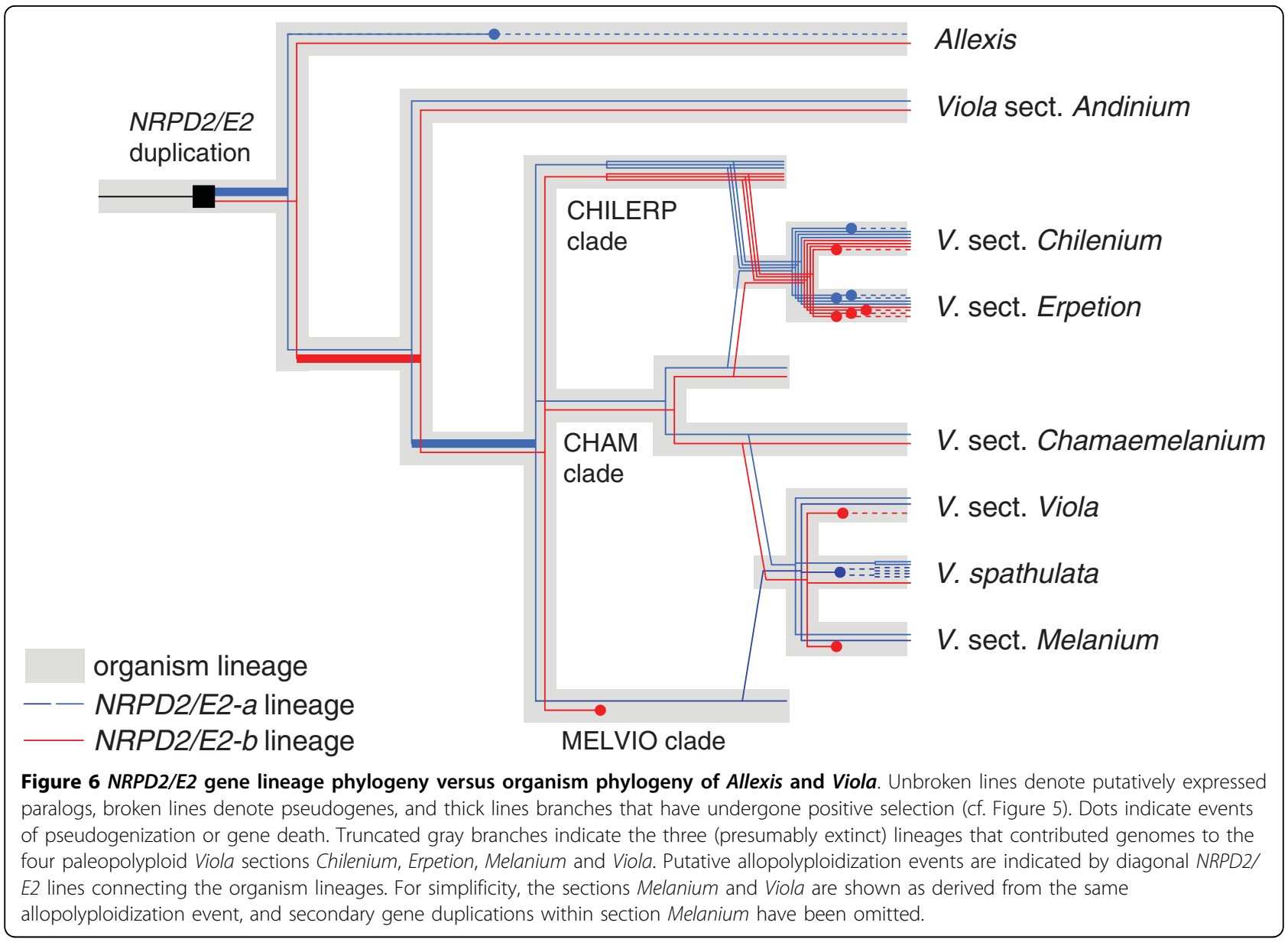

paralogs that are substantially more divergent than in the Sileneae and that may result from an older duplication (Brysting AK, Mathiesen C, Marcussen T, in prep.). Thus, it may be that the small NRPD2/E2 gene family is subject to massive concerted evolution between paralogs, as already indicated in Silene by gene conversion (loss of NRPD2/E2-b and duplication of NRPD2/E2-a) within one lineage. Due to these factors it may be hard to pinpoint the duplication event on a phylogenetic tree.

Within the Violaceae, there are certain indications from ongoing research that the original duplication of NRPD2/E2 may be connected with whole genome duplications via allopolyploidy. Recent findings for the genus Ionidium, which belongs to the same clade as Anchietea and Corynostylis in the present study, based on karyology (Seo MN, Sanso AM, Xifreda CC, unpublished) and a low-copy nuclear gene (unpublished data), suggest that the currently accepted base chromosome number $(x=8)$ for this genus, and for large parts of the family, is in fact tetraploid. There is some evidence of paleaotetraploidy also in Viola as, apart from NRPD2/E2, also several other low-copy genes have been found to be duplicated, i.e. chalcone synthase [37], shikimate dehydrogenase (unpublished data) and homeotic floral genes (Ballard HE, personal communication).

Most Viola groups were found to have a more or less balanced number of NRPD2/E2- $a$ and NRPD2/E2-b copies. Presumably due to redundancy following polyploidy, massive pseudogenization of this gene family has happened in the paleopolyploid sections Chilenium and Erpetion. However, the situation is very different in the other two polyploid sections, Viola and Melanium. These two sections have their allopolyploid origin in one or several wide hybridization events between two major diploid clades, CHAM and MELVIO. The CHAM clade, today represented by the diploid section Chamaemelanium, has apparently functional copies of both NRPD2/E2-a and NRPD2/E2-b, while the MELVIO clade, which is now extinct as diploid, has secondarily lost its NRPD2/ $E 2-b$ paralog. Assuming subneofunctionalization of the two paralogs (which is suggested by positive selection, see below), this would mean that the remaining MELVIO paralog, which is by phylogenetic origin an "A" paralog, must have regained the ancestral expression state performing both "A" and "B" functions. Thus, the sections Viola and Melanium inherited one paralog of each 
NRPD2/E2- $a$ and NRPD2/E2- $b$ from the CHAM ancestor, and from the MELVIO an NRPD2/E2- $a$ paralog with both "A" and "B" function. This "incomplete redundancy" in the polyploids may have lead to further gene death within the two sections. In species belonging to these sections ( $V$. spathulata excepted), the current CHAM NRPD2/E2-b paralog is either a pseudogene (section Viola except $V$. hirta) or has been completely lost (section Melanium and V. hirta), while having two NRPD2/ E2-a copies, one derived from CHAM and a second from MELVIO. In $V$. spathulata all the MELVIO paralogs have been pseudogenized and only the CHAM-derived paralogs are expressed; this was, apparently, also followed by a more recent polyploidization event.

Thus, both sections Viola and Melanium, although tetraploid, possess putatively functional NRPD2/E2 copies only of $N R P D 2 / E 2-a$, derived from the ancestral MELVIO and CHAM genomes. As both these seem functional, and have not suffered the same fate as the NRPD2/E2- $b$ paralog during the same period of time, it may be that some degree of de novo subfunctionalization has evolved between these two NRPD2/E2-a paralogs. Further research is needed to shed light upon this issue.

\section{Positive selection is seen in regions associated with subunit interaction}

In cases with ongoing neofunctionalization following gene duplication, one would expect positive selection to be acting on parts of one or both paralogs, and $d_{N}$ to be larger than $d_{S}$ [e.g., [38]]. Our findings for NRPD2/E2 fit well with these assumptions: only purifying selection was detected among taxa with singleton $N R P D 2 / E 2$; while soon after duplication of the gene in the common ancestor of Allexis and Viola both NRPD2/E2 paralogs seem to have been subjected to rapid sub- and neofunctionalization. This is detected as $d_{N} / d_{S}$ ratios larger than 1 along these branches, indicating positive selection, especially early in the divergence process (Figure 6). This process appears to have happened at different times in NRPD2/E2- $a$ and in NRPD2/E2- $b$. Our branch analysis suggests rapid specialization of NRPD2/E2- $a$ in the common ancestor of Allexis and Viola while for $N R P D 2 / E 2-b$, positive selection occurred at a later time and only in Viola, not in Allexis. Compared to Viola, higher redundancy in Allexis due to a still incomplete complementation of the two paralogs, may have facilitated pseudogenization of NRPD2/E2-a in A. batangae.

It is likely that the $54 \mathrm{bp}$ region is important for the specialization and neofunctionalization of the two NRPD2/E2 paralogs in Viola. Crystallography of yeast Pol II has shown that this region of the second-largest subunit (Nrpb2) is part of a "hybrid binding" domain that is involved in subunit recognition and binding [2].
The first half of this region corresponds to an ordered loop interacting with the tenth-largest subunit (Nrpb10) and its second half forms an $\alpha$-helix that interacts with the third-largest subunit (Nrpb3). Since structure and function tend to be conserved over all eukaryot Pols [2] and, especially, because of the close phylogenetic relationship between the Pol II and Pol IV/V subunit genes [3], we can assume that this region of Nrpd2/Nrpe2 interacts with homologs of Nrpd3 and Nrpd10. Under the assumption that the differentiation of NRPD2/E2-a and NRPD2/E2- $b$ reflect specialization with respect to Pol IV and V, we suggest that this region is important for correct recognition of subunits specific to Pol IV and Pol V in Viola. This likely applies also to duplicated $N R P D 2 / E 2$ in other eudicot lineages, and in this respect the between-paralog divergence of the very same region also in Silene [10] is noteworthy.

In Arabidopsis thaliana the exact subunit compositions of Pol IV and Pol V are known [1]. In this species, only a single copy of NRPD2/E2 is expressed (although another very similar duplicate is pseudogenized) and its protein product assembles with both Pol IV and Pol V [1]. Of the two subunit genes with whose gene products Nrpd2-a and Nrpd2-b interact, the NRPD10 homolog is not duplicated in Arabidopsis and shared between Pols II, IV and IV. NRPD3/E3, however, exists in two rather similar paralogs $(85 \%$ sequence similarity at the protein level) that are incompletely subfunctionalized between Pol II/V and Pol V and apparently have been under positive selection (not shown). In the other genome sequenced eudicots, Populus trichocarpa and Vitis vinifera, neither of these genes are duplicated. If, however, $N R P D 3 / E 3$ is duplicated in Viola and Violaceae, in addition to the basal differentiation of NRPD1 and NRPE1, this could give some indications about how NRPD2/E2 came to be duplicated in this angiosperm family.

\section{Conclusions}

Aspects of the build, function and origin of the two atypical plant RNA polymerases Pol IV and Pol V are a hot topic in current research. This knowledge has in turn opened for study the dynamics of the origin and specialization of the individual subunits and their co-evolution within a phylogenetic framework.

Herein, we have presented the first documentation of possible co-evolution among subunits of Pol IV/V, from within the angiosperm family Violaceae. Following duplication, NRPD2/E2- $a$ and NRPD2/E2- $b$, encoding $\mathrm{Pol} I V / V$ subunits, underwent rapid specialization (neofunctionalization) in a region that is important for subunit interaction and recognition. We conclude that correct recognition of the type-specific subunits is important for the correct function of each of Pol IV and Pol V. 
Our study on Violaceae and previous studies on Caryophyllaceae draw a picture of $N R P D 2 / E 2$ as a young gene family, still in the process of diverging and specializing and still subject to strong concerted evolution among paralogs. The few species and genera that have been studied show a variable number of Pol IV/V gene copies. Since the divergence of Pol IV and Pol V seems to have only barely preceded the radiation of the angiosperms, we can expect their young gene families to have acquired different lineage-specific specializations within angiosperms.

\section{Methods \\ Material}

The investigated 18 species of Viola (Table 1) were selected so as to cover the taxomomic diversity (i.e. following Ballard et al. [26]), geographical diversity and ploidal levels of the genus Viola. Represented in this study were Viola section Andinium (South America; V. congesta), section Chilenium (South America; V. maculata), section Erpetion (eastern Australia; V. banksii), section Chamaemelanium (mainly East Asia and North America; 4 species), section Melanium (mainly Mediterranean; 3 species) and section Viola (northern hemisphere; 7 species). Six outgroup taxa (Table 1) were selected from within Violaceae, of which Allexis was known to be phylogenetically close to Viola [25], and non-Violaceae outgroups from within the Malpighiales, Populus trichocarpa (Salicaceae), Manihot esculenta and Euphorbia esula (Euphorbiaceae).

\section{DNA isolation}

DNA was extracted using a CTAB extraction protocol [39]. In most cases stock DNA was diluted 20 times for working solutions of which $1 \mu \mathrm{l}$ was used per 20-40 $\mu \mathrm{l}$ PCR reaction. For "difficult" DNA preparations, where higher template amounts or cleaner template were needed in the PCR reaction, the obtained stock DNA solution was further cleaned using the DNeasy Blood \& Tissue Kit (Qiagen, Düsseldorf, Germany), following the manufacturer's guidelines except that the first 2 steps were omitted; the obtained working solution was not diluted, and 5-10 $\mu$ l were used in 80-160 $\mu$ PCR reactions divided into an appropriate number of tubes.

\section{PCR and sequencing}

Primer sequences and standard PCR conditions are presented in Table 2. The nomenclature of exons and introns follows the terminology in Arabidopsis. The NRPD2/E2 locus, ranging from exon 5 through most of exon 7 , was in most taxa amplified in two PCRs with overlapping range, one PCR covering exon 5 through intron 6 using the primers 5F2898 and Svex7R3420, and a second covering exon 6 through exon 7 using the primers vex6F3263 and 7R3883 (Figure 1). This approach was preferred to amplifying the entire locus in a single PCR, because (1) it increases the chance of discovering all paralogs (especially for pseudogenes where the primer binding sites are no longer conserved), because (2) it reduces the amount of $\mathrm{PCR}$ recombination which is expected to increase with gene copy number, their similarity and length of the amplified fragment [cf. [40]]. Where one of the PCRs failed (notably for the outgroup taxa for which DNA was extracted from herbarium material and of inferior quality), shorter stretches of DNA were sought amplified in three separate PCRs, (1) using the primer pairs 5F2898 (or 5F3062) and vex6R3371, (2) vex6F3263 and Svex7R3420, and (3) vex7F3418 and 7R3883. The primers were designed based on DNA sequences available on GenBank, and in some cases based on already existing Viola sequence data.

PCR products were separated by electrophoresis on $1 \%$ agarose gels, and multiple bands were cut out separately and cleaned using the E.Z.N.A. Gel Extraction Kit (Omega Bio Tek, Doraville, GA, USA) following the manufacturer's manual. Some cleaned products were sequenced directly, but generally these were cloned using the TOPO TA Cloning Kit (Invitrogen, Carlsbad, CA, USA) according to the manufacturer's manual, with the exception that only half of the volumes recommended for the reactions were used. Between 3 and 20 positive colonies from each reaction were screened by direct PCR using primers TOPO_F

Table 2 Standard PCR and sequencing primers, primer combinations and annealing temperatures used

\begin{tabular}{llll}
\hline Region & Forward primer & Reverse primer & Annealing temperature \\
\hline ex5-in6 (PCR 1) & 5F2898: TTGACAGCCTYGATGATGAT & Svex7R3420: ATCTTGAAAATCCAGCCC \\
ex5-in6 & 5F3062: AATGATGASGGGAAGAATTTGC & Svex7R3420 & 52 ${ }^{\circ} \mathrm{C}$ \\
ex6-ex7 (PCR 2) & vex6F3263: GYCARCTYCTTGAGGCTGC & 7R3883: ATVCCCATGCTGAAKAGCTCYTG & $52^{\circ} \mathrm{C}$ \\
ex5-ex6 & 5F2898 & vex6R3371: YMTCRACACTGGGAGTGGAG & $54^{\circ} \mathrm{C}$ \\
ex5-ex6 & 5F3062 & vex6R3371 & $57^{\circ} \mathrm{C}$ \\
ex6-in6 & vex6F3263 & Svex7R3420 & $52^{\circ} \mathrm{C}$ \\
ex7 & vex7F3418: GGCTGGATTTCAAGATGG & 7R3883 & $55^{\circ} \mathrm{C}$
\end{tabular}

PCR mix: 20 to $40 \mu \mathrm{l}$ reactions; $0.2 \mathrm{mM}$ dNTPs, $0.25 \mu \mathrm{M}$ of each of the primers, $1 \times$ Phusion HF buffer, $0.008 \mathrm{U} / \mu \mathrm{l}$ Phusion polymerase. The PCR conditions were as follows: initial denaturation at $95^{\circ} \mathrm{C}$ for $30 \mathrm{~s}$ followed by 35 cycles of $95^{\circ} \mathrm{C}$ for $9 \mathrm{~s}$, annealing at a temperature specified below for $30 \mathrm{~s}$, and $72^{\circ} \mathrm{C}$ for $30 \mathrm{~s}$. The $\mathrm{PCR}$ ended with $7: 30$ minutes at $72^{\circ} \mathrm{C}$ and subsequent soak at $10^{\circ} \mathrm{C}$. 
(GGCTCGTATGT-TGTGTGGAATTGTG) and TOPO_R (AGTCACGACGTTGTAAAACGACGG). PCR products were diluted 10 times and sequenced one way using either T7 or M13R universal primer. Sequencing was done with BigDye 3.1 sequencing Kit (Applied Biosystems, Foster City, CA, USA) on 3730 ABI DNA analyzer (Applied Biosystems).

All sequence chromatograms were controlled manually and sequence alignments established in BioEdit [41] by manual adjustments. Indel characters were coded by using the simple gap-coding method in SeqState [42] and appended to the alignment. Four data alignment matrices were generated; these are available as additional files 1, 2, 3 and 4. (1) The first (Violaceae) matrix (see Additional file 1) consisted of intron and exon sequences of Allexis batangae, Anchietea parvifolia, Corynostylis arborea, Cubelium concolor, Hybanthus enneaspermus, Rinorea ilicifolia, Viola biflora and V. congesta aligned to an outgroup consisting of GenBank exononly sequences of non-Violaceae Populus trichocarpa, Manihot esculenta and Euphorbia esula. (2) The second (Viola) matrix (see Additional file 2) consisted of all Viola sequences aligned to Allexis batangae sequences (outgroup). (3) The third matrix (see Additional file 3) was used to examine $d_{N} / d_{S}$ ratios with a sliding window approach using the DnaSP software, and consisted of only exon sequences of all the non-Viola Violaceae sequences along with all NRPD2/E2- $a$ and NRPD2/E2- $b$ sequences of $V$. congesta, $V$. banksii, $V$. maculata, $V$. biflora, $V$. brevistipulata, $V$. nuttallii and $V$. pubescens. (4) The fourth matrix (see Additional file 4) was used to estimate individual $d_{N} / d_{S}$ ratios for phylogenetic branches using the PAML software; this matrix consisted of a reduced data set of the 44 Violaceae taxa having unidentical NRPD2/E2 sequences (i.e., duplicate sequences were removed) within a 54 bp exon domain in which positive selection was detected in the DnaSP analysis. Rinorea was used as outgroup.

\section{Phylogenetic reconstruction}

The Violaceae and Viola matrices were used for phylogenetic reconstruction. Owing to a large number of sequences in the Viola matrix NRPD2/E2- $a$ and NRPD2/ $E 2-b$ were analyzed separately, using maximum parsimony (MP) and maximum likelihood (ML). MP analyses of all three data sets were performed with TNT version 1.1 [43], using traditional search, tree bisection-reconnection (TBR) branch swapping, 10 replicates (number of added sequences), and 10 trees saved per replication. Maximum Parsimony bootstrap analyses were carried out with the same settings and with 1000 replicates. Maximum Likelihood analyses of all three data sets were performed with Treefinder version of March 2008 [44] and run with different nucleotide substitution models for the three partitions of the sequence data: exons, introns and coded indels. Nucleotide substitution models for the exon and intron partitions were proposed by Treefinder, while for coded indels a uniform rate model (Jukes-Cantor) was applied (in Treefinder this substitution model had to be specified as "HKY $[\{1,1,1,1,1,1\}$, Optimum]:GI [Optimum]:4"). The Violaceae matrix (1) was analyzed using the 4-rate model $\mathrm{J} 1+\mathrm{I}+\mathrm{G}$ ( TA = TG; CA = CG) for both exons and introns. The Viola matrix (2) was analyzed with the 3-rate model $\mathrm{TN}(\mathrm{TA}=\mathrm{TG}=\mathrm{CA}=\mathrm{CG})$ for exons and the 4-rate model $\mathrm{J} 1+\mathrm{I}+\mathrm{G}(\mathrm{TA}=\mathrm{TG}$; $\mathrm{CA}=$ CG) for introns. Mamimum Likelihood bootstrap analyses were carried out with the same settings and with 100 replicates.

\section{Detection of gene duplication in Violaceae}

The obtained NRPD2/E2 phylogeny was incongruent with the organism phylogeny of Violaceae, and so we further analyzed the Violaceae matrix for possible gene recombination and/or duplication events. The GeneTree software [45] was used to construct a reconciled tree by embedding the NRPD2/E2 tree within the Violaceae species tree. The Violaceae species tree was obtained from re-analysis of Tokuoka's [25] 4-gene data set of atpB, mat $\mathrm{K}, r b c \mathrm{~L}$ and $16 \mathrm{~S}$ for a taxon subset corresponding to the one used in this study. Cubelium concolor was not included in Tokuoka's phylogeny but a mat $\mathrm{K}$ sequence was available on GenBank (EF135550, as Hybanthus concolor). In order to firmly place Cubelium in the family phylogeny and to compensate for weaker data for this taxon, we also included in our analysis Orthion subsessile, which has been considered close to Cubelium on morphological grounds [34]. Maximum Parsimony and ML analyses were carried out as above, except for ML using a 6-rate substitution model GTR+G. To screen the Violaceae alignment for possible recombination we employed the Genetic Algorithms for Recombination Detection (GARD) [46,47], on the exons only, using general parameter settings (GTR model of nucleotide substitution and beta-gamma rate variation with 2 rate classes). We then separated the alignments at the detected breakpoints within the region, estimated MP phylogenetic trees (1000 bootstrap replicates) for the individual sections, and checked for incongruent topologies.

\section{Detection of positive selection}

Estimating $d_{N}$ (the number of nonsynonymous substitutions per nonsynonymous site) and $d_{S}$ (the number of synonymous substitutions per synonymous site) between coding sequences is useful for detecting whether there has been purifying selection $\left(d_{N} / d_{S}<1\right)$, neutral evolution $\left(d_{N} / d_{S}=1\right)$ or positive selection $\left(d_{N} / d_{S}>1\right)$.

For data matrix 3 (exons), the polymorphism and divergence module of the DnaSP package [48], using the 
sliding window option, were used to make a graphic representation of the pattern of change of $d_{N} / d_{S}$ ratios along the sequence. We generated three sequence categories that were each compared to Rinorea (which is sister to the other examined Violaceae taxa). The first category consisted of all taxa (except Rinorea) having singleton NRPD2/E2, i.e. Corynostylis, Cubelium and Hybanthus. The second category consisted of 13 NRPD2/E2- $a$ exon sequences from Allexis and Viola ( $V$. congesta, 2 of $V$. banksii, 3 of $V$. maculata, $V$. biflora, $V$. brevistipulata, 3 of $V$. nuttallii and $V$. pubescens). The third category consisted of $10 N R P D 2 / E 2-b$ exon sequences from the same Viola taxa as for the second category. As DnaSP does not support gaps nor stop codons, pseudogenes (except for Allexis NRPD2/E2-a, because of its phylogenetic position) and incomplete sequences (e.g., Anchietea NRPD2/E2 and Allexis NRPD2/E2-b) had to be omitted. Within Viola, taxa of the sections Melanium and Viola were omitted because they do not possess functional copies of both NRPD2/ $E 2-a$ and NRPD2/E2-b.

For the $54 \mathrm{bp}$ region for which positive selection was detected with DnaSP, we used the CodeML software of the PAML package [49] to further determine at which branches in the phylogeny positive selection had occurred. A simplified organism phylogeny was used as input tree file due to the short length $(54 \mathrm{bp})$ of the sequence analyzed (Figure 5).

Additional file 1: Violaceae matrix. This file represents the NRPD2/E2 alignment from 8 Violaceae taxa aligned to exon sequences of a nonViolaceae outgroup.

Click here for file

[http://www.biomedcentral.com/content/supplementary/1471-2148-1045-S1.TXT]

Additional file 2: Viola matrix. This file represents the alignment of NRPD2/E2 copies from 18 Viola taxa aligned to Allexis batangae as outgroup.

Click here for file

[http://www.biomedcentral.com/content/supplementary/1471-2148-1045-S2.TXT ]

Additional file 3: DnaSP Positive selection sliding window matrix. This file represents the alignment of 27 NRPD2/E2 exon sequences from Violaceae taxa used to examine $d_{N} / d_{S}$ ratios with a sliding window approach using the DnaSP software.

Click here for file

[http://www.biomedcentral.com/content/supplementary/1471-2148-1045-S3.TXT ]

Additional file 4: PAML positive selection matrix. This file represents the 54 basepair alignment of NRPD2/E2 exon sequences for 44 Violaceae taxa.

Click here for file

[http://www.biomedcentral.com/content/supplementary/1471-2148-1045-S4.TXT]

\section{Acknowledgements}

We thank Kim Blaxland and Gerd Knoche for providing plant material, and two anonymous reviewers for reading and commenting on a previous version of this manuscript. Nicola Barson is thanked for correcting the language. This work was supported by the Norwegian Research Council (grant no. 170832: "Allopolyploid evolution in plants: patterns and processes within the genus Viola") and the Swedish Research Council (grant no. 20063766).

\section{Author details}

${ }^{1}$ Centre for Ecological and Evolutionary Synthesis (CEES), Department of Biology, University of Oslo, 0316 Oslo, Norway. ${ }^{2}$ Department of Plant and Environmental Sciences, University of Gothenburg, SE-40530 Göteborg, Sweden.

\section{Authors' contributions}

TM designed the study, collected material, contributed the molecular studies, performed the phylogenetic and selection analysis and led the writing of the manuscript. AS contributed to the molecular studies. BO and KSJ participated in the coordination and design of the study, interpretation of the results and writing of the manuscript. All authors read and approved the final manuscript.

Received: 16 May 2009

Accepted: 16 February 2010 Published: 16 February 2010

\section{References}

1. Ream TS, Haag JR, Wierzbicki AT, Nicora CD, Norbeck A, Zhu JK, Hagen G, Guilfoyle TJ, Paša-Tolić L, Pikaard CS: Subunit compositions of the RNAsilencing enzymes Pol IV and Pol V reveal their origins as specialized forms of RNA Polymerase II. Mol Cell 2009, 33:192-203.

2. Cramer $P$, Bushnell DA, Kornberg RD: Structural basis of transcription: RNA polymerase II at 2.8 Ångström resolution. Science 2001, 292(5523):1863-1876.

3. Luo J, Hall BD: A multistep process gave rise to RNA polymerase IV of land plants. J Mol Evol 2007, 64(1):101-112.

4. Onodera Y, Haag J, Ream T, Nunes P, Pontes O, Pikaard C: Plant nuclear RNA polymerase IV mediates siRNA and DNA methylation-dependent heterochromatin formation. Cell 2005, 120(5):613-622.

5. Wierzbicki AT, Haag JR, Pikaard CS: Noncoding transcription by RNA Polymerase Pol IVb/Pol V mediates transcriptional silencing of overlapping and adjacent genes. Cell 2008, 135(4):635-648.

6. Oxelman B, Yoshikawa N, McConaughty BL, Luo J, Denton AL, Hall BD: $R P B 2$ gene phylogeny in flowering plants, with particular emphasis on asterids. Mol Phylogenet Evol 2004, 32(2):462-479.

7. Jaillon O, Aury J-M, Noel B, Policriti A, Clepet C, Casagrande A, Choisne N, Aubourg S, Vitulo N, Jubin C, et al: The grapevine genome sequence suggests ancestral hexaploidization in major angiosperm phyla. Nature 2007, 449(7161):463-468.

8. Vilatersana R, Brysting AK, Brochmann C: Molecular evidence for hybrid origins of the invasive polyploids Carthamus creticus and C. turkestanicus (Cardueae, Asteraceae). Mol Phylogenet Evol 2007, 44(2):610-621.

9. The Arabidopsis Genome Initiative: Analysis of the genome sequence of the flowering plant Arabidopsis thaliana. Nature 2000, 408:796-815.

10. Popp M, Oxelman B: Evolution of a RNA polymerase gene family in Silene (Caryophyllaceae) - incomplete concerted evolution and topological congruence among paralogues. Syst Biol 2004, 53(6):914-932.

11. Ralph S, Oddy C, Cooper D, Yueh H, Jancsik S, Kolosova N, Philippe RN, Aeschliman D, White R, Huber D, et al: Genomics of hybrid poplar (Populus trichocarpa $\times$ deltoides) interacting with forest tent caterpillars (Malacosoma disstria): normalized and full-length CDNA libraries, expressed sequence tags, and a CDNA microarray for the study of insect-induced defences in poplar. Mol Ecol 2006, 15(5):1275-1297.

12. Kong $\mathrm{H}$, Landherr LL, Frohlich MW, Leebens-Mack J, Ma H, dePamphilis CW: Patterns of gene duplication in the plant SKP1 gene family in angiosperms: evidence for multiple mechanisms of rapid gene birth. Plant J 2007, 50(5):873-885

13. Town CD, Cheunga F, Maitia R, Crabtree J, Haasa BJ, Wortmana JR, Hinea EE, Althoffa R, Arbogasta TS, Tallona $L$, et al: Comparative genomics of Brassica oleracea and Arabidopsis thaliana reveal gene loss, fragmentation, and dispersal after polyploidy. Plant Cell 2006, 18:1348-1359.

14. Tuskan GA, Difazio S, Jansson S, Bohlmann J, Grigoriev I, Hellsten U, Putnam N, Ralph S, Rombauts S, Salamov A, et al: The Genome of Black 
Cottonwood, Populus trichocarpa (Torr. \& Gray). Science 2006, 313(5793):1596-1604.

15. Yang $X$, Tuskan GA, Cheng Z-M: Divergence of the Dof gene families in poplar, Arabidopsis, and rice suggests multiple modes of gene evolution after duplication. Plant Physiol 2006, 142:820-830.

16. Force A, Lynch M, Pickett FB, Amores A, Yan Y-L, Postlethwait J: Preservation of duplicate genes by complementary, degenerative mutations. Genetics 1999, 151:1531-1545.

17. Hughes AL: The evolution of functionally novel proteins after gene duplication. Proc Biol Sci 1994, 256(1346):119-124.

18. Hittinger C, Carroll S: Gene duplication and the adaptive evolution of a classic genetic switch. Nature 2007, 449(7163):677-681.

19. He X, Zhang J: Rapid subfunctionalization accompanied by prolonged and substantial neofunctionalization in duplicate gene evolution. Genetics 2005, 169:1157-1164.

20. Drea SC, Lao NT, Wolfe KH, Kavanagh TA: Gene duplication, exon gain and neofunctionalization of OEP16-related genes in land plants. Plant J 2006, 46(5):723-735.

21. Akhunov ED, Akhunova AR, Dvorak J: Mechanisms and rates of birth and death of dispersed duplicated genes during the evolution of a multigene family in diploid and tetraploid wheats. Mol Biol Evol 2007, 24(2):539-550.

22. Wang R, Chong K, Wang T: Divergence in spatial expression patterns and in response to stimuli of tandem-repeat paralogues encoding a novel class of proline-rich proteins in Oryza sativa. J Exper Biol 2006, 57(11):2887-2897.

23. Federico ML, Iñiguez-Luy FL, Skadsen RW, Kaeppler HF: Spatial and temporal divergence of expression in duplicated barley germin-like protein-encoding genes. Genetics 2006, 174(1):179-190.

24. Munzinger J, Ballard HE: Hekkingia (Violaceae), a new genus of arborescent violet from French Guiana, with a key to genera in the family. Syst Bot 2003, 28(2):345-351.

25. Tokuoka T: Molecular phylogenetic analysis of Violaceae (Malpighiales) based on plastid and nuclear DNA sequences. J Plant Res 2008, 121:253-260.

26. Ballard HE, Sytsma K, Kowal RR: Shrinking the violets: Phylogenetic relationships of infrageneric groups in Viola (Violaceae) based on internal transcribed spacer DNA sequences. Syst Bot 1998, 23(4):439-458.

27. Miyaji Y: Untersuchungen über die Chromosomezahlen bei einigen ViolaArten. [In Japanese]. Bot Mag Tokyo 1913, 27:443-460.

28. Marcussen T, Nordal I: Viola suavis, a new species in the Nordic flora, with analyses of the relation to other species in the subsection Viola (Violaceae). Nord J Bot 1998, 18(2):221-237.

29. Nordal I, Jonsell B: A phylogeographic analysis of Viola rupestris: Three post-glacial immigration routes into the Nordic area?. Bot I Linn Soc 1998, 128(2):105-122.

30. Sanso AM, Seo MN: Chromosomes of some Argentine angiosperms and their taxonomic significance. Caryologia 2005, 58(2):171-177.

31. Clausen J: Cytotaxonomy and distributional ecology of western North American violets. Madroño 1964, 17:173-197.

32. Ballard HE, Sytsma KJ: Evolution and biogeography of the woody Hawaiian violets (Viola, Violaceae): Arctic origins, herbaceous ancestry and bird dispersal. Evolution 2000, 54(5):1521-1532.

33. Álvarez I, Wendel JF: Ribosomal ITS sequences and plant phylogenetic inference. Mol Phylogenet Evol 2003, 29:417-434.

34. Feng M: Floral morphogenesis and molecular systematics of the family Violaceae. PhD Athens: Ohio University 2005.

35. Yoo KO, Jang SK, Lee WT: Phylogeny of Korean Viola based on ITS sequences. Korean J Plant Taxon 2005, 35(1):7-23, (in Korean).

36. Fior S, Karis PO, Casazza G, Minuto L, Sala F: Molecular phylogeny of the Caryophyllaceae (Caryophyllales) inferred from chloroplast matK and nuclear rDNA ITS sequences. Amer J Bot 2006, 93(3):399-411.

37. Hof van den $\mathrm{K}$, Berg van den RG, Gravendeel B: Chalcone synthase gene lineage diversification confirms allopolyploid evolutionary relationships of European rostrate violets. Mol Biol Evol 2008, 25(10):2099-2108.

38. Yang Z: Likelihood ratio tests for detecting positive selection and application to primate lysozyme evolution. Mol Biol Evol 1998, 15(5):568-573.

39. Gabrielsen TM, Bachmann K, Jakobsen KS, Brochmann C: Glacial survival does not matter: RAPD phylogeography of Nordic Saxifraga oppositifolia. Mol Ecol 1997, 6:831-842.
40. Popp M, Oxelman B: Inferring the history of the polyploid Silene aegaea (Caryophyllaceae) using plastid and homoeologous nuclear DNA sequences. Mol Phylogenet Evol 2001, 20(3):474-481.

41. Hall TA: BioEdit: a user-friendly biological sequence alignment editor and analysis program for Windows 95/98/NT. Nuc Acids Symp Ser 1999, 41:95-98.

42. Müller K: SeqState - primer design and sequence statistics for phylogenetic DNA data sets. Appl Bioinform 2005, 4:65-69.

43. Goloboff PA, Farris JS, Nixon KC: TNT, a free program for phylogenetic analysis. Cladistics 2008, 24:774-786.

44. Jobb G, von Haeseler A, Strimmer K: TREEFINDER: a powerful graphical analysis environment for molecular phylogenetics. BMC Evol Biol 2004, 4(18):9.

45. Page RDM: GeneTree: comparing gene and species phylogenies using reconciled trees. Bioinformatics 1998, 14(9):819-820.

46. Rieseberg $L H$, Baird SJE, Gardner KA: Hybridization, introgression, and linkage evolution. Plant Mol Ecol 2000, 42(1):205-224.

47. Kosakovsky Pond SL, Posada D, Gravenor MB, Woelk CH, Frost SD: Automated phylogenetic detection of recombination using a genetic algorithm. Mol Biol Evol 2006, 23(10):1891-1901.

48. Rozas J, Sánchez-DelBarrio JC, Messeguer X, Rozas R: DnaSP, DNA polymorphism analyses by the coalescent and other methods. Bioinformatics 2003, 19:2496-2497.

49. Yang Z: PAML 4: Phylogenetic Analysis by Maximum Likelihood. Mol Biol Evol 2007, 24(8):1586-1591.

50. Holmgren PK, Holmgren NH: [continuously updated]. Index Herbariorum: A global directory of public herbaria and associated staff. New York Botanical Garden's Virtual Herbarium. 1998http://sweetgum.nybg.org/ih/.

doi:10.1186/1471-2148-10-45

Cite this article as: Marcussen et al:: Evolution of plant RNA polymerase IV/V genes: evidence of subneofunctionalization of duplicated NRPD2/ NRPE2-like paralogs

in Viola (Violaceae). BMC Evolutionary Biology 2010 10:45.

\section{Submit your next manuscript to BioMed Central and take full advantage of:}

- Convenient online submission

- Thorough peer review

- No space constraints or color figure charges

- Immediate publication on acceptance

- Inclusion in PubMed, CAS, Scopus and Google Scholar

- Research which is freely available for redistribution
C Biomed Central 